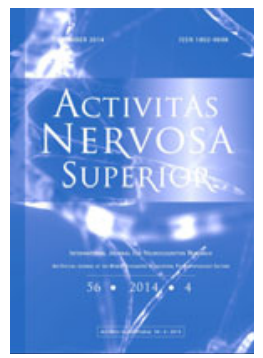

\title{
SOCIODEMOGRAPHIC AND CLINICAL CHARACTERISTICS OF VICTIMIZED VERSUS NON- VICTIMIZED PATIENTS WITH SCHIZOPHRENIA: AN EGYPTIAN STUDY
}

\author{
Ahmed El Missiry, Marwa Abd El Meguid," Marwa Soltan, Marwa El Missiry \\ Institute of Psychiatry, Neuropsychiatry Department, Faculty of Medicine, Ain Shams University, Cairo, Egypt
}

\begin{abstract}
Persons with mental disorders living in the community are liable for victimization and are considered as a high-risk group. Objective of this study was to explore the sociodemographic variables and clinical characteristics related to victimization of patients with schizophrenia in comparison to their nonvictimized counterparts. One hundred patients were recruited from the inpatient wards and outpatient clinics of the Institute of Psychiatry, Ain Shams University. They were subjected to Structured Clinical Interview for DSM-IV Axis I diagnosis (Clinical Version); Positive and Negative Syndrome Scale (PANSS); Global Assessment of Functioning (GAF); Clinical Global Impression (CGI); designed extensive questionnaire to elicit demographic data; inquiry about drug compliance and Victimization Questionnaire. Results show that 70 patients of the studied sample were non-victimized and 30 patients were victimized. Victimized patients were significantly younger, living mainly in urban areas, had less frequent history of bullying at school. There were exposed significantly to higher frequency of family domestic violence and childhood abuse. They scored higher for all subscales and in total PANSS scores and they were less compliant on medication than did their non-victimized counterparts. Until now studies of victimization of mentally ill did not draw the attention of researchers and clinicians in Arab world. This study proves that victimization is not uncommon among patients with schizophrenia; Clinicians should include assessment for victimization of their patients as a routine work. The current study provides preliminary data for clinicians and policy makers to consider strategies to protect patients with various mental illnesses from being victimized.
\end{abstract}

Key words: Victimization; Schizophrenia; Sociodemographic; Severity

\section{INTRODUCTION}

Persons with mental disorders, especially those with severe mental illness, living in the community are liable for crime victimization and are considered as high-risk group (Hiday et al., 2002; Teplin et al., 2005). Victimization is largely operationally defined as either covert/relational victimization or overt/physical victimization, in which a person is threatened with or dealt corporeal damage (Cole et al., 2010). Criminal victimization is a

\footnotetext{
*Correspondence to: Marwa Abd El Meguid, e-mail: melmeguid@gmail.com [Translated with permission from The Arab Journal of Psychiatry 2011, 22, 148-157.]

Received September 3, 2012; accepted October 22, 2013; Act Nerv Super 56(4), 121-134; ISSN-1802-9698
} 
serious and pervasive problem for people who are homeless and seriously mentally ill (Lam \& Rosenheck, 1998). Chuang et al. (1987) found that patients with schizophrenia were three times more likely to be victims of violent crime than persons who did not have a mental illness. Teplin et al. (2005) estimated that $25 \%$ of mentally ill are victimized in comparison to $3 \%$ of the general population. Walsh et al. (2003) estimated that $16 \%$ of patients with psychosis were violently victimized over one year. Choe et al. (2008) have concluded in his study that $2 \%$ to $13 \%$ of mentally ill had perpetrated violence in the past six months of his study to three years, compared with $20 \%$ to $34 \%$ who had been violently victimized; indicating that victimization of mentally ill is of greater importance than perpetration of violence by mentally ill.

Individuals who have schizophrenia have been said to represent a potentially vulnerable population that is at risk of significant victimization in the community (Lehman, 1999). Brekke et al. (2001) studied 172 outpatient clients with schizophrenia, they found that $38 \%$ of patients had been victimized within the preceding 3 years; $91 \%$ of the incidents were violent. They are at increased risk of victimization, both of the violent and non-violent type (Fitzgerald et al., 2005); violent victimization includes rape and sexual assault, robbery, and physical assault (US Department of Justice, 2001). Moreover, Lam and Rosenheck (1998) concluded that past victimization has a significant impact on two important areas of client outcome; it had a significant impact on clinical outcomes in terms of increased homelessness and decreased quality of life, and moreover it is predictive of future victimization. They viewed that victimization perpetuates homelessness, lowers self-rated quality of life, and decreases the likelihood of employment.

Walsh et al. (2003) showed that those who have been victimized were significantly more likely to feel threatened and unsafe than others and consequently it is more likely that they will engage in violence themselves. It is therefore conceivable that victimization and violence in severe mental illness share a common pathway and that the occurrence of one or both outcomes will be determined by complex interactions between these factors across the life cycle, indicating that an individual's own violence may only explain a proportion of violent victimization in the sample. Furthermore, the link between severe mental illness and violent victimization has been shown to be independent of an individual's own tendency towards violence (Silver, 2002).

Many causes were attributed to the increased risk of victimization of mentally ill, such as impaired reality testing, disorganized thought processes, impulsivity, poor planning and problem solving can compromise one's ability to perceive risks and protect oneself (Goodman et al., 1997; Hiday et al., 1999; Marley \& Buila, 2001). On the other hand, several predictors of victimization among homeless persons were identified: severe psychiatric symptoms, substance abuse (Lam \& Rosenheck, 1998; Brekke et al., 2001), concurrent personality disorder (Walsh et al., 2003), lack of meaningful daily activities (Fitzgerald et al., 2005), poor financial support (Honkonen et al., 2004), conflicted social relationships, poverty, and homelessness are factors correlated with victimization (Miethe \& Mc Dowall, 1993; Logan et al., 2001; Silver et al., 2005). Moreover, individual risk for victimization varies according to demographic and psychosocial characteristics. Most important among these risk factors are sex, race, employment status, social environment, economic status, poor physical health, criminal history and history of victimization (Ascher-Svanum et al., 2006). Regarding employment; Lam and Rosenheck (1998) have found that the relationship between employment and victimization is noteworthy. The more days a client had worked in the past month, the more likely he or she was to have been a recent crime victim. This association may be due to the fact that workers are more likely to be carrying money and thus to be targets of crime. Hiday (1997) posited a theoretical model whereby social disorganization and poverty phenomena are common among many persons with severe mental illness increasing persons' vulnerability to victimization and their propensity to perpetrate violence. Repeated victimization may lead to suspicion and mistrust, which in turn may lead to conflictive and stressful situations in short, a cycle of victimization and perpetration. 
Finally, Lam and Rosenheck (1998) concluded that the most severe psychiatric symptoms, substance abuse problems and criminal histories are caught in a vicious, reinforcing cycle of victimization and homelessness. The effect of violence goes beyond the physical consequences and includes "psychological demoralization and the ever-present fear and distrust of others frequently reported by homeless people".

Aim: The aim of this study was to explore the sociodemographic variables and clinical characteristics including severity of symptomatology and level of functioning in patients with schizophrenia who were victimized in comparison to their non-victimized counterparts.

\section{SUBJECTS AND METHODS}

Site of study

Patients were recruited from the inpatient wards and outpatient clinics of the Institute of Psychiatry, Ain Shams University. The institute is located in Eastern Cairo and serves a catchment area of about the third of Greater Cairo. It serves both urban and rural areas, including areas around Greater Cairo as well.

\section{Participants}

The sample was a convenient one; males and females patients were included, aged 18 years or older. They are fulfilling the diagnosis of schizophrenia according to DSM IV as a primary diagnosis not secondary to substance misuse. Subjects had to have been ill for more than one year with absence of organic brain damage. The researchers interviewed potential participants and explained the details of the research goals, ensured that the obtained data will be confidential and that participants could withdraw from the study at any time, and those who refused to participate or withdraw during the interview were excluded $(n=18)$. The recruitment continued until we had 100 patients with different types of schizophrenia included. The research including the pilot study was performed during the period from June 2008 till the end of January 2010.

Preparation and pilot study

Prior to the pilot study, the research team prepared the Victimization questionnaire to collect data from patients about being victimized. It was adapted from the Criminal Victimization Questionnaire Package, 2009 and the Juvenile Victimization Questionnaire "JVQ" (Finkelhor et al., 2005). The questionnaire included questions about conventional crime like: personal theft, robbery, burglary, vandalism, assault with or without weapon, attempted assault, biased physical and verbal assault, kidnapping, threatening, blackmailing, sexual harassment either verbal or physical, emotional abuse, financial abuse or any type of physical abuse. The overall Cronbach $\alpha$ for the JVQ for respondents answering all 34 items is .80 , which is very good (Finkelhor et al., 2005). The questionnaire was translated to Arabic and back translated to English and was applied on 30 patients with different psychiatric disorders; the language was readjusted to fit to the Egyptian culture according to patients' comprehension. The research team was trained on the use of tools prior to the study; the team included both junior and senior psychiatrists who were responsible for data collection.

The study proper

It started after the period of pilot study, interviewing was performed in the assessment office in the inpatient department or the outpatient clinics. The average time needed to complete the 
patient interview was about 90 to 120 minutes, sometimes divided in two sessions according to patient's cooperativeness.

Tools

1. Structured Clinical Interview for DSM-IV Axis I diagnosis Clinical Version (First et al., 1995): a semistructured diagnostic interview based on an efficient but thorough clinical evaluation administered by an experienced trained bilingual researcher to match Arabic speaking patients. SCID-I was used in previous Egyptian studies (Assad et al., 1992; El Missiry, 2003; Hatata et al., 2004; El Ghonemy et al., 2005).

2. Positive \& Negative Syndrome Scale (PANSS) used for measuring symptom severity of patients with schizophrenia (Kay et al., 1987). The PANSS was used in research on Egyptian population (Okasha et al., 2005).

3. Global Assessment of Functioning (GAF) is a numeric scale (0 through 100) to rate subjectively the social, occupational, and psychological functioning of adults, e.g., how well or adaptively one is meeting various problems in living (Jones et al., 1995). The GAF had been used on Egyptian patients (Awad, 2001).

4. Clinical Global Impression (CGI) (Guy, 1976): is a 7-point scale that requires the clinician to rate the severity of the patient's illness at the time of assessment, relative to the clinician's past experience with patients who have the same diagnosis. Considering total clinical experience, a patient is assessed on severity of mental illness at the time of rating. Previous study on Egyptian patients had been used before (Awad, 2001).

5. Designed extensive questionnaire to elicit demographic, other information and inquiry about drug compliance. Also we used Fahmi and El Sherbini Scale (1988) for social class determination.

6. Victimization questionnaire developed by the researchers.

\section{Ethical issue}

Ethical approval of the protocol of research was obtained by the authority of Ain Shams University Ethical and Research Committee. The researchers described the study to the patients, ensured the confidentiality of information and obtained their informed consent for participation. It was stated that the participation in the study was voluntary and they have the freedom to withdraw from the assessment at any time.

\section{Statistical analysis}

Data analysis was done using Statistical Package for Social Sciences Version-15 (SPSS-15). Student's T test $(\mathrm{t})$ was used for comparison between means of the different groups. Pearson Chi-Square Test $(\chi 2)$ was used for comparison between qualitative variables. P value was used to indicate the level of significance where $P \leq 0.05$ is considered significant (SIG), $P \leq 0.01$ is highly significant (HS), $\mathrm{P} \leq 0.001$ is (VHS) very highly significant. Logistic regression analysis which is used for prediction of the probability of occurrence of an event by fitting data to a logistic curve.

\section{RESULTS}

\section{Sociodemographic variables}

The studied sample was constituted from 60 male and 40 female patients labeled the diagnosis of schizophrenia according to the DSM IV classification. It was found that 70 patients of the whole population were non-victimized and 30 patients were victimized hence the studied 
group was divided into; the non-victimized group (mean age 35 \pm 9.1 ) and the victimized group (mean age $30 \pm 6.2$ ). Data in table 1 revealed that the victimized patients were significantly younger $(p=0.028)$, living mainly in urban areas $(p=0.004)$, and had less frequency history of bullying at school $(p=0.017)$ than their non-victimized counterparts although the majority of victimized patients were exposed to bullying. There was no statistical difference between the two groups as regard gender, marital status, occupational status, type of work, educational attainment and social standards (Table 1).

Table 1. Sociodemographic characteristics: victimized versus non-victimized patients

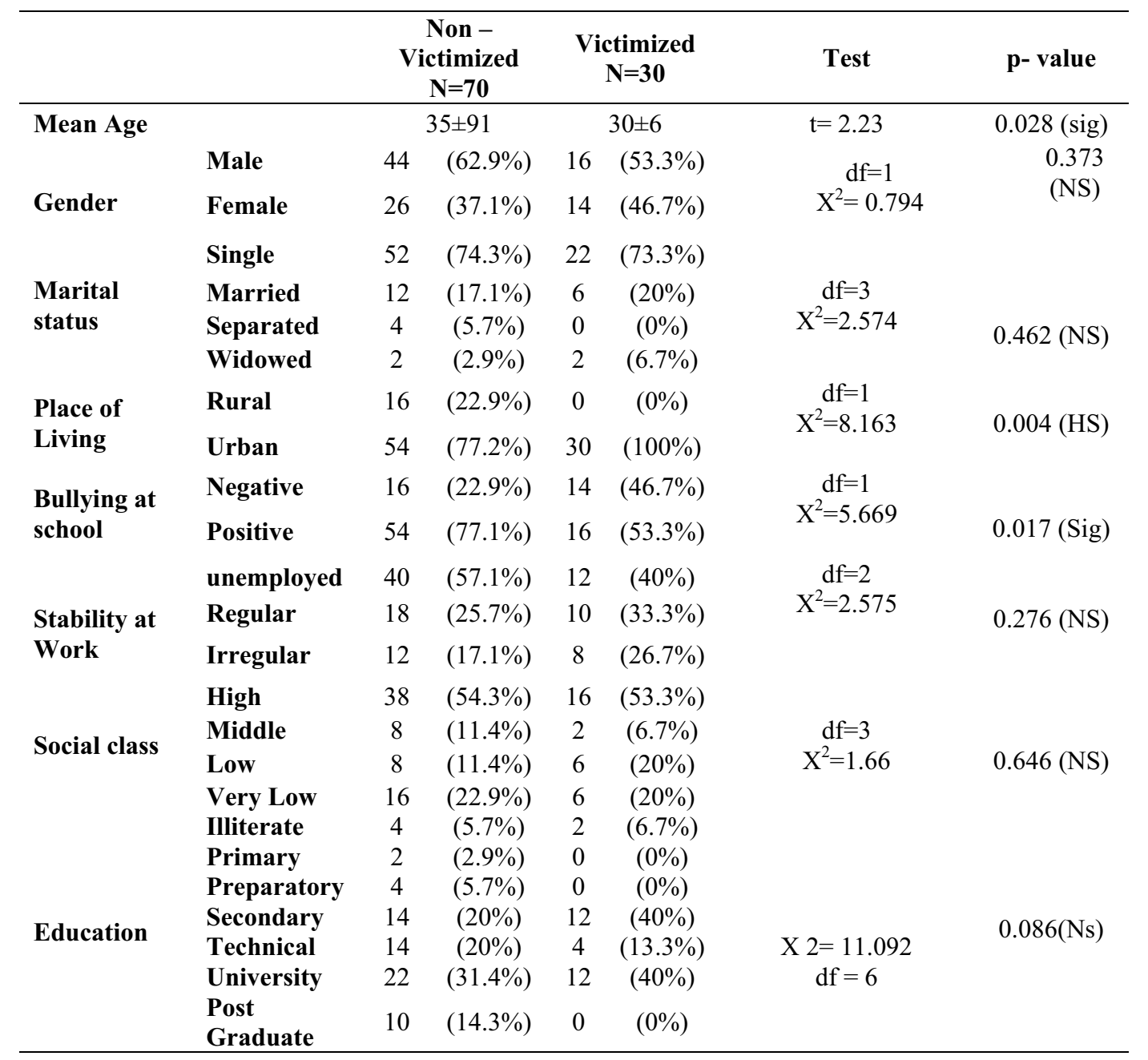

Exposure to violence

According to data displayed in table 2; victimized patients exposed significantly to higher frequency of family domestic violence $(p=0.005)$, surprisingly in the victimized group, violence towards father was found in $20 \%$ while towards mother was in $13.3 \%$ compared to only $2.9 \%$ and $5.7 \%$ towards father and mother respectively in the non-victimized group.

According to the definition of child abuse by WHO, 1999 which referred to all forms of physical and/or emotional ill-treatment, sexual abuse, neglect or negligent treatment or commercial or other exploitation, resulting in actual or potential harm to the child's health, 
survival, development or dignity in the context of a relationship of responsibility, trust or power." Inquiry about child abuse in our research, we found that there were statistical differences between the two groups of study $(p=0.000)$, victimized patients exposed to more emotional and physical abuse in their childhood than non-victimized patients.

Neither history of parental separation by divorce or early parent's death nor the age at the time of separation affect being later on victimized or non-victimized (Table 2).

Family history of psychiatric disorders was encountered more significantly in the non victimized group $(34.3 \%)$ compared to $(13.3 \%)$ in the victimized patients $(p=0.048)$. On the other hand, no significant differences was found between the studied groups as regards family history of drug and alcohol abuse $(\mathrm{p}=0.087)$ (Table 2).

\section{Clinical Profile}

Severity of illness was assessed by PANSS revealed that victimized patients were scored higher than non-victimized group in all subscales and in total PANSS score $(p=0.000)$. They had more significant positive symptoms (including delusions, conceptual disorganization, hallucinatory behavior, excitement, grandiosity, suspiciousness and hostility), negative symptoms (including blunted affect, emotional and social withdrawal, difficulty in abstract thinking), and they obtained also significant higher scores on general psychopathology (including presence of anxiety and depression, poor attention, disorientation, lack of judgment, poor impulse control). Data in (Table 3) indicates that the more severity on PANSS scores, the more, the likelihood of being victimized.

It was noticed that the Global Assessment of Functioning "GAF" scores of victimized group was slightly lower than the non-victimized group with no statistical difference between both groups.

Table 2. Family Characteristics: victimized versus non-victimized patients.

\begin{tabular}{|c|c|c|c|c|c|c|c|}
\hline & \multirow[b]{2}{*}{ Negative } & \multicolumn{2}{|c|}{$\begin{array}{c}\text { Non -Victimized } \\
\mathbf{N}=70\end{array}$} & \multicolumn{2}{|c|}{$\begin{array}{c}\text { Victimized } \\
\mathbf{N}=\mathbf{3 0}\end{array}$} & & \multirow[t]{2}{*}{ p- value } \\
\hline \multirow{4}{*}{$\begin{array}{l}\text { Parental } \\
\text { separation }\end{array}$} & & 46 & $(65.7 \%)$ & 20 & $(66.7 \%)$ & \multirow{4}{*}{$\begin{array}{c}\mathrm{df}=3 \\
\mathrm{X}^{2}=5.685\end{array}$} & \\
\hline & Divorced & 8 & $(11.4 \%)$ & 4 & $(13.3 \%)$ & & \multirow{3}{*}{0.128 (NS) } \\
\hline & Early death & 16 & $(22.9 \%)$ & 4 & $(13.3 \%)$ & & \\
\hline & $\begin{array}{l}\text { Working } \\
\text { Abroad }\end{array}$ & 0 & $(0 \%)$ & 2 & $(6.7 \%)$ & & \\
\hline \multicolumn{2}{|c|}{ Age of separation } & & $5.06 \pm 8.423$ & & $8.27 \pm 12.292$ & $\mathrm{t}=-1.512$ & $0.134(\mathrm{NS})$ \\
\hline \multirow{3}{*}{$\begin{array}{l}\text { Family } \\
\text { Domestic } \\
\text { Violence }\end{array}$} & Negative & 64 & $(91.4 \%)$ & 20 & $(66.7 \%)$ & \multirow{3}{*}{$\begin{array}{c}\mathrm{df}=2 \\
\mathrm{X}^{2}=10.771\end{array}$} & \\
\hline & To mother & 4 & $(5.7 \%)$ & 4 & $(13.3 \%)$ & & 0.005 (HS) \\
\hline & To father & 2 & $(2.9 \%)$ & 6 & $(20 \%)$ & & \\
\hline \multirow{3}{*}{$\begin{array}{l}\text { Child } \\
\text { Abuse }\end{array}$} & Negative & 66 & $(94.3 \%)$ & 18 & $(60 \%)$ & \multirow{3}{*}{$\begin{array}{c}\mathrm{df}=3 \\
\mathrm{X}^{2}=18.685\end{array}$} & \multirow{3}{*}{$\begin{array}{c}0.000 \\
\text { (VHS) }\end{array}$} \\
\hline & Emotion. & 2 & $(2.9 \%)$ & 8 & $(26.7 \%)$ & & \\
\hline & Physical & 2 & $(2.9 \%)$ & 4 & $(13.3 \%)$ & & \\
\hline \multirow{5}{*}{$\begin{array}{l}\text { F.H of } \\
\text { Psych. } \\
\text { Illness }\end{array}$} & Negative & 46 & $(65.7 \%)$ & 26 & $(86.7 \%)$ & \multirow{5}{*}{$\begin{array}{c}\mathrm{df}=3 \\
\mathrm{X}^{2}=6.085\end{array}$} & \multirow{5}{*}{0.048 (Sig) } \\
\hline & $1^{\text {st }}$ degree & 14 & $(20 \%)$ & 4 & $(13.3 \%)$ & & \\
\hline & $2^{\text {nd }}$ degree & 10 & $(14.3 \%)$ & 0 & $(0 \%)$ & & \\
\hline & Abuse & 12 & $(17.1 \%)$ & 4 & $(13.3 \%)$ & & \\
\hline & Depend. & 0 & $(0 \%)$ & 2 & $(6.7 \%)$ & & \\
\hline
\end{tabular}


Compliance to medication was obtained by asking the patient to self rate their compliance; it was found that victimized patients were less compliant than those who are not victimized with a high statistical significant difference between both groups (table 3 ).

Assessment of the whole group by the Clinical Global Impression "CGI" revealed that the degree of severity was found to be statistically significant $(p=0.011)$ as victimized group was evaluated to be more among severely ill or extremely ill than the non-victimized group. Although the degree of improvement did not differ statistically $(p=0.714)$ between the two groups, yet it was noticed that the victimized patients showed higher non statistical significant minimal improvement $(26.7 \%)$ in comparison to $(20 \%)$ of the non-victimized group (Table 4 ).

Concerning putative risk factors associated with victimization of patients with schizophrenia; Logistic regression analysis was performed to explore these risk factors: It was found as displayed in table (5) that the greatest risk is the place of living, (being in urbanized place) followed by low scores on the level of functioning as measured by GAF, then comes the higher exposure to child abuse, then the greater severity of illness as measured by the total scores of PANSS. Other factors were not found to be significant risk factors.

Table 3. Mean Scores of PANSS, GAF and Compliance rates: victimized versus non-victimized patients.

\begin{tabular}{lcccc}
\hline PANSS & $\begin{array}{c}\text { Non }- \text { Victimized } \\
\text { mean } \pm \text { SD }\end{array}$ & Victimized & $\begin{array}{c}\text { 95\% Confidence } \\
\text { Interval }\end{array}$ & p-value \\
& $20.14 \pm 7.897$ & $26.80 \pm 7.797$ & $-10.064 ;-3.250$ & $0.000(\mathrm{HS})$ \\
Positive symptoms & $23.97 \pm 10.562$ & $28.57 \pm 10.637$ & $-9.917 ;-0.012$ & 0.049 (Sig.) \\
Negative symptoms & $26.29 \pm 13.886$ & $35.03 \pm 10.692$ & $-14.387 ;-3.108$ & $0.003(\mathrm{HS})$ \\
General & $70.26 \pm 25.096$ & $90.43 \pm 24.517$ & $-30.970 ;-9.382$ & $0.000(\mathrm{HS})$ \\
psychopathology & $32.8 \pm 7.44$ & $31.23 \pm 7.016$ & $-4.666 ; 1.523$ & $0.316(\mathrm{NS})$ \\
GAF PANSS scores & $60.29 \pm 29.11$ & $40 \pm 33.83$ & $7.03 ; 33.532$ & $0.006(\mathrm{HS})$ \\
\hline Compliance Rate &
\end{tabular}

Note: PANSS: Positive and Negative Syndrome Scale; GAF: Global Assessment of Functioning

Table 4. Clinical Global Improvement: victimized versus non-victimized patients.

\begin{tabular}{|c|c|c|c|c|c|c|}
\hline \multirow[b]{2}{*}{ CGI severity } & \multicolumn{2}{|c|}{ Non-Victimized } & \multicolumn{2}{|c|}{ Victimized } & \multirow[t]{2}{*}{ test } & \multirow[t]{2}{*}{ P-value } \\
\hline & $\mathrm{N}$ & $\%$ & $\mathrm{~N}$ & $\%$ & & \\
\hline Moderately ill & 14 & $20 \%$ & 0 & $0 \%$ & \multirow{6}{*}{$\begin{array}{c}X 2=11.111 \\
\text { df }=3\end{array}$} & \multirow{5}{*}{$\begin{array}{l}0.011 \\
\text { significant }\end{array}$} \\
\hline Markedly ill & 0 & $0 \%$ & 2 & $6.7 \%$ & & \\
\hline Severely ill & 52 & $74.3 \%$ & 26 & $86.7 \%$ & & \\
\hline Extremely ill & 4 & $5.7 \%$ & 2 & $6.7 \%$ & & \\
\hline Total & 70 & $100 \%$ & 30 & $100 \%$ & & \\
\hline CGI Improvement & & & & & & \multirow{6}{*}{$\begin{array}{l}0.714 \\
\text { Non } \\
\text { significant }\end{array}$} \\
\hline Not assessed & 2 & $2.9 \%$ & 0 & $0 \%$ & \multirow{5}{*}{$\begin{array}{c}X 2=11.363 \\
\text { df }=3\end{array}$} & \\
\hline Very much improved & 16 & $22.9 \%$ & 6 & $20 \%$ & & \\
\hline Much improved & 38 & $54.3 \%$ & 16 & $53.3 \%$ & & \\
\hline Minimally Improved & 14 & $20 \%$ & 8 & $26.7 \%$ & & \\
\hline Total & 70 & $100 \%$ & 30 & $100 \%$ & & \\
\hline
\end{tabular}

Note: CGI: Clinical global Improvement 
Table 5. Putative risk factors found to be significant for victimization (Regression analysis).

\begin{tabular}{lccc}
\hline Risk Factors & t-value & p-value & Significance \\
\hline Place of Living & 3.616 & 0.001 & HS \\
GAF & 3.156 & 0.002 & HS \\
Childhood Abuse & 3.105 & 0.003 & HS \\
PANSS-Total score & 2.413 & 0.018 & Sig \\
Family domestic Violence & 2.150 & 0.035 & Sig \\
\hline
\end{tabular}

Note: Other studied variables were found to be non significant risk factors

\section{DISCUSSION}

Patients with schizophrenia are at increased risk of being victims of violent and non violent crime (Shomerus et al., 2008). Teplin et al. (2005) stated that the incidence of violent crime was 4 times greater among persons with severe mental illness than the incidence reported in general population. The disturbed behavior in schizophrenia is sometimes culturally attributed to acts of possession by spirits, jinni, sorcery, or envy-eye (Khalil, 2001). This in itself can predispose to a unique type of physical abuse since families with such beliefs usually take their patients to traditional healers who hit them, or even suffocate them in order to get rid of the evil spirit or jinni (Ragheb et al., 2009).

Sociodemographic variables

The current study assessed the sociodemographic variables related to victimization of patients with schizophrenia to identify factors which potentiate victimization of those patients and assess the severity and clinical profile of victimized patients versus non-victimized patients. We found that 30 out of 100 patients with schizophrenia were victimized (30\%). The recorded rate in our study (despite the sample was not a representative one) is considered average in comparison to the prevalence found in previous studies done by Brekke et al. (2001), who found that $38 \%$ of 172 patients were victimized and Teplin et al. (2005), who recorded that $25.3 \%$ in his study were victimized. Lower rates were found by Walsh et al. (2003) (16\% to 18\%); Brunette and Drake (1997) (18.3 \%) and Hiday et al. (2002) (10\%). Differences in the recorded rates may be attributed to differences in the sampling methods, tools of assessment and definition of victimization.

In the current study we found that victimized patients were significantly younger than non-victimized patients. Similar results were found in study done by Walsh et al. (2003), Brekke et al. (2001) and Lehman \& Linn (1984). Hiday et al. (1999) studied a sample of patients with severe mental illness in different age group from 19 years old till 65 years; they found that the prevalence of exposure to violent and non violent crimes was higher in patients with age ranging from $18-29$ followed by those ranging from $30-44$; they found that the least prevalence was among those above 65 years of age. These could be attributed to the tendency of older patients to stay at home more than younger persons thus reducing their exposure to crime from strangers outside their homes (Khalil, 200; Ragheb et al., 2009). On the other hand, younger patients are exposed to threatening conditions both outside and inside their homes (Sampson \& Lauristen, 1993; Klaus, 2000). On the contrary, Fitzgerald et al. (2005) did not find significant difference between age of victimized and non-victimized patients in his sample.

In the current study, more men $(53.3 \%)$ than women $(46.7 \%)$ were victimized, however, no significant statistical differences were found in comparison to non-victimized patients. Hiday et al. (1999) found that more men were exposed to violent crime however more females were exposed to non violent crime. Also, Lam \& Rosenhech (1998) have found that women were more likely than men to have been victims. This difference could be explained in the context of the cultural background of the Egyptian society which may consider violence against women especially from strangers outside home is a shame. In our study, marital status was not found 
to be a risk factor for being victimized compared to other studies which stated that living without a partner or spouse may expose patients with schizophrenia to the threat of being victimized (Walsh et al., 2003; Fitzgerald et al., 2005).

Living in urban rather than rural areas is one of the most important risk factors related to the exposure of patients with schizophrenia to victimization. According to previous findings which stated that many people with mental illness in villages in the developing world are better accepted, less stigmatized, less victimized and more likely to find work in the subsistence agricultural economy or to engage in meaningful labor (Al Asraa \& Amin, 1988; Sartorius et al., 1996; Okasha, 1999; Okasha et al., 2000). In contrast, patients with schizophrenia in urban regions were significantly exposed to stigmatization, discrimination and victimization (Owaida et al., 1990; Kamel et al., 1991). In an interesting study in Al Mansoura University, Egypt, Fawzy et al. (1984) found that paranoid schizophrenia was more common in urban than rural men because they are more prone to stressful reaction such as loss of sympathizing relations with neighbors, friends and relatives, as well as loosening of family ties. These factors start to threaten the psychic stability and make one loses trust in others. In western communities, there are controversial findings, while Honkonen et al. (2004) revealed no urban - rural difference found among his victimized patients with schizophrenia, Castalano (2006) and Hiday et al. (1999) reported that patients living in urban areas were more exposed to victimization.

Our research did not prove a relation between the level of education and being victimized, it was observed that around $80 \%$ of victimized patients were either having secondary or university education. Some researchers found that having higher educational level increased victimization (Hiday et al., 1999); contrary to the expected inverse association. Previous research has found a similar relationship between level of education and perceptions of coercion (Hiday et al., 1997). It was noticed in our study that working pattern was not found to differ statistically between the two groups; moreover it is worth to mention that the victimized group of patients were enrolled in regular jobs more often than the non-victimized. This finding (despite being surprising) it could be explained by the extreme need of the victimized patient to earn money, being rejected by their relatives, in addition to the possibility of exposure to threatening circumstances outside their homes and work places.

Exposure to violence

A statistical significant difference was found regarding history of bullying at school; it was noticed that $53.3 \%$ of victimized patients had a positive history of bullying at school; this is consistent with previous findings which concluded that being a victim of bullying is associated with internalizing problems including affective disorder, anxiety disorder or psychotic disorder (Fekkes et al., 2006; Kumpulainen, 2008; Menisini et al., 2009).

In our study exposure to family domestic violence was one of the risk factors of being victimized $(p=0.035)$. Surprisingly, we noticed that among the victimized group, we found that violence towards fathers $(20 \%)$ exceed that directed towards mothers $(13.3 \%)$. This finding could reflect the lack of patient's development in normal family having two adequate parental figures, and the development of skewed relationship between the patient and his parents who are a defective one (may be the father) and domineering demanding one (may be the mother). This leads to unsatisfactory parenting model and interpersonal relationship (Okasha, 1988).

We agreed with the statement saying that being victimized in childhood will lead to victimization in adulthood (Coid et al., 2001). Our study emphasized that exposure to child abuse is one of the important putative risk factors for being victimized $(p=0.003)$. Coid et al (2001) concluded that childhood maltreatment increase the risk of adulthood revictimization; in other words domestic violence and victimization are interrelated and potentiating each other he added that child abuse, bullying at school, self abuse by psychoactive substances, 
expressed emotions by relatives or employers are intermingled factors in producing victimization.

\section{Family history of psychiatric illness}

Non-victimized patients had a more significant family history of psychiatric illness than victimized patients; this finding may reflect that families with psychiatric illnesses have more tolerance to mental symptoms of their offspring (Okasha, 1999). Family climate plays an important role in the inter-personal relationship in families with schizophrenia. In this respect, the concept of expressed emotions has gained ground in the field of psychiatry. It includes five component; criticism, hostility, emotional over involvement, warmth and positive remarks (Abou Saleh et al., 1998). In Egyptian community, unexpectedly, many reports found high values of warmth among families of patients with schizophrenia which may cause better enhancement of their psychosocial adjustment (Sampson \& Lauristen, 1993; Sartorius, Gulbinat, \& Harrison, 1996). Moreover, Okasha et al. (1994), concluded that criticism is an accepted and acceptable component of interpersonal relations in Egyptian culture and that it might well reflect an element of care. It is also possible that criticism and over involvement are intertwined and that warmth might act as a key protective factor.

\section{Clinical Assessment}

The current study revealed that the victimized patients were more likely to have severe form of symptoms according to PANSS in positive, negative and general psychopathology; other studies found similar results (Brekke et al., 2001; Walsh et al., 2003; Fitzgerald et al., 2005). Shomerus et al. (2008) found that the level of positive symptoms was associated with the experience of victimization indicating that the more the disturbed patient the more vulnerability of being victimized. Fitzgerald et al. (2005) stated that patients with positive symptoms such as persecutory delusions could report victimization events that have not actually occurred; falsely elevating the rates of reported victimization. The current study proved that a greater severity of clinical symptoms as measured by the Clinical Global Improvement scale "CGI" was associated with a higher probability of being victimized. This was confirmed in previous studies in this field (Hiday, 1995; Bloom et al., 2000; Brekke et al., 2001; Hiday, 2002; Walsh, 2003).

\section{Level of functioning}

The level of functioning of the studied group was estimated using the Global Assessment of Functioning scale "GAF"; data revealed that no statistical differences were found between both groups despite the difference in severity. Although Fitzgerald et al. (2005) have found that the major predictors of victimization in his studied sample was among those who had no substantial daily activities and those with high degree of psychosocial disability.

Compliance to medication was found to be lower in victimized group than non-victimized with a high statistical significant difference. Previous studies revealed that non adherence is also associated with poor social outcomes, including greater risk of arrest, violence, victimization, and substance use and poorer mental functioning and life satisfaction (Weiden et al., 2004; Ascher-Svanum et al., 2006; Law et al., 2008). Hiday et al. (2002) reported 74.9\% of a sample of patients with schizophrenia who were exposed to crime victimization during the year following their discharge from hospital to be non compliant. Also, Torrey (1999) concluded based on previous study by Hiday et al. (1995) that there is a direct relationship between medication noncompliance and criminal victimization, which could be observed anecdotally among patients. Medication adherence can be expected to reduce symptoms of severe mental illness and thus reduce victimization (Hiday et al., 2002). Psychotic symptoms and bizarre behavior can lead to tense and conflictual situations (Hiday, 1997), which, in turn, 
may result in a patient's victimization either because others become violent toward the patient or because the patient lashes out physically and others react with stronger violence. By facilitating adherence and ensuring more consistent follow-up, outpatient commitment may lead to reduced symptoms, better functioning in social relationships, and improved judgment (Bloom et al., 2000). This finding enlightens the interrelation which could be present between severity of illness, compliance and victimization. In other words, lack of compliance will lead to more severity of illness hence increasing exposure to victimization; also being victimized especially by family members reveal negligence and rejection hence non compliance will be more pronounced.

Studies of victimization of mentally ill did not draw the attention of researchers and clinicians in Arab world. This study prove that victimization is not uncommon among patients with schizophrenia; being more pronounced in those who have more severe symptomatology and non compliance to medication. Patients who were exposed to victimization were male, single and living in urban area. Domestic violence, history of child abuse and bullying at school were among variables correlated with current victimization. The presence of family history of psychiatric illness was not associated with victimization. Clinicians should include assessment for victimization of their patients as a routine work. The current study provides preliminary data for clinicians and policy makers to consider strategies to protect patients with various mental illnesses from being victimized.

To the best of our knowledge, this is the first Egyptian study done to estimate prevalence of victimization in a sample of patients with schizophrenia and to examine their sociodemographic and clinical characteristics. However, some limitations in our study must be acknowledged and taken into account. As the sample was convenient; the result of our study could not be generalized, however should be considered as preliminary results. Future studies including larger sized random sample could provide further important information. Moreover correlation to specific symptomatology should be considered in further studies. The victimization questionnaire being specially designed for this research, we relied on the reliability and validity of the original tools from which it was derived, however, the need of future use for standardization on Egyptian population is recommended. Studies of other categories of mental and psychiatric disorders are highly recommended to provide data about victimization of mentally ill patients in Egyptian community and in various Arab Countries.

\section{REFERENCES}

Abol-Magd, S. (1993). Psychiatric Assessment of families of Schizophrenic patients. MD Thesis, Faculty of Medicine, Cairo University.

Abou Saleh, M.T., Karim, L., \& Krymski M. (1998). Biological aspects of schizophrenia in Arab Culture, Current Psychiatry, 5, 23-30.

Al Asraa, A. \& Amin, H. (1988). Hospital Admission in a psychiatric division in Saudi Arabia. Saudi Medical Journal, 9, 25-33.

Ascher-Svanum, H., Faries, D.E., Zhu, B., Ernst, F.R., Swartz, M.S., \& Swanson, J.W. (2006). Medication adherence and long-term functional outcomes in the treatment of schizophrenia in usual care. Journal of Clinical. Psychiatry, 67, 453-460.

Assad, T., Okasha, A., Kamel, H., Zakaria, M. (1992). Psychiatric morbidity after cerebrovascular accidents. M.D thesis, Ain Shams University.

Awad, M.A. (2001). Study of the role of Atypical Antipsychotic Drugs on the different stages and severity of Schizophrenia. Master thesis supervised by El Sheshai A; Rashed S; Salama H. Faculty of medicine Alexandria University.

Bloom, J.D., Mueser, K.T., Muller-Isberner, R. (2000). Treatment implications of the antecedents of criminality and violence in schizophrenia and major affective disorders. In Violence Among the Mentally Ill: Effective Treatment and Management Strategies. Edited by Hodgins S. Dordrecht, the Netherlands, Kluwer Academic 145-169

Bloom, J.D., Mueser, K.T., \& Muller-Isberner, R. (2000). Treatment implications of the antecedents of criminality and violence in Schizophrenia and major affective disorders In Violence Among ther 
Mentally ill: Effective Treatment and Management Strategies. Edited by Hodgins S. Dordrecht, The Netherlands, Kluwer Academic, 145-169.

Brekke, J.S., Prindle, C., Bae, S.W., \& Long, J.D. (2001). Risks for individuals with schizophrenia who are living in the community. Psychiatric Services, 52, 1358-1366.

Brunette, M.F. \& Drake, R.E. (1997). Gender differences in patients with schizophrenia and substance abuse. Comprehensive Psychiatry, 38, 109-116.

Castalano, S.M. (2006). Criminal victimization, (2005). Bureau of Justice Statistics Bulletin, US. Department of Justice (www.ojp.usdoj.gov/bjs/pub/pdf/cv05.pdf). Accessed 23 November,

Choe, J.Y., Teplin, L.A., \& Abram, K.M. (2008). Perpetration of Violence, Violent Victimization, and Severe Mental Illness: Balancing Public Health Concerns. Psychiatric Services, 59, 153- 164.

Chuang, H.T., Williams, R., \& Dalby, J.T. (1987). Criminal ehavior among schizophrenics. Canadian Journal of Psychiatry, 32, 255-258.

Coid, J., Petruckevitch, A., Feder, G., Chung, W., Richardson, J., \& Moorey, S. (2001). Relation between childhood sexual and physical abuse risk of revictimization in women: A cross sectional survey. Lancet, 358, 450- 454 .

Cole, D.A., Maxwell, M.A., Dukewich, T.L., \& Yosick, R. (2010). Targeted peer victimization and the construction of positive and negative self-cognitions: Connections to depressive symptoms in children. Journal of Clinical Child and Adolescent Psychology, 39, 421-435

Criminal Victimization Questionnaire Package for the General Social Survey. Main Survey Cycle 23. Social and Aboriginal .Statistics Division. Statistics Canada, Ontario. 2009

El Ghonemy, S., Lotaief, F., Assad, T., Essawy, H., Haroun El Rasheed, A. (2005). Relapse Predictors in Egyptian Substance Use Disorder Patients. MD Thesis, Ain Shams University.

El Missiry, A. (2003). Homicide and Psychiatric Illness, An Egyptian Study. MD thesis Faculty of Medicine, Ain Shams University,

Fahmy, S.I. \& EL Sherbini, A.F. (1988). Determining simple parameters for social classification for health researchers. The Bulletine of the High Institute of Public Health, 95-108.

Fawzy, A., Khater, M., El Boraie, M., \& El-Atrony, M. (1984). Sociocultural aspects of Paranoid states and paranoid schizophrenia. A comparative study. The Egyptian Journal of Psychiatry, 47-55.

Fekkes, F., Pijpers, FI., Fredriks, A.M., Vogels, T., \& Verloove-Vanhorick, S.P. (2006). Do bullied children get ill, or do ill children get bullied? A prospective cohort study on the relationship between bullying and health related symptoms. Pediatrics, 117, 1568- 1574.

Finkelhor, D., Hamby, S.L., Ormrod, R., Turner, H. (2005). The Juvenile Victimization Questionnaire: reliability, validity, and national norms. Child Abuse and Neglect, 29, 383-412.

First M.B., Spitzer R.L., Williams W. et al (1995). Structured Clinical Interview for DSM-IV Axis I Disorders (SCID-I). In Handbook of Psychiatric Measures. Washington, American Psychiatric Association.

Fitzgerald PB., De Castella A., Filia K., Filia S., Benitez J. and Kulkarni J. (2005): Victimization of patients with schizophrenia and related disorders. Australian and New Zealand Journal of Psychiatry;39(3), 169-174

Goodman LA, RosenbergSD, Mueser KT, Drake RE (1997): Physical and sexual assault history in women with serious mental illness: Prevalence Correlates, treatment and future research directions. Schizophrenia Bulletin.; 23:685-696.

Guy, W. (1976). ECDEU Assessment Manual for Psychopharmacology - Revised (DHEW Publ No ADM 76-338). Rockville, MD, U.S. Department of Health, Education, and Welfare, Public Health Service, Alcohol, Drug Abuse, and Mental Health Administration, NIMH Psychopharmacology Research Branch, Division of Extramural Research Programs, 218-222.

Hatata, H.A., Khalil, A.H., Assad, T., AboZeid, M.Y., \& Okasha, T.A. (2004). Dual diagnosis in substance use disorder, a study in Egyptian sample. MD Thesis, Ain Shams University.

Hiday, V.A., Swartz, M., Swanson, J.W., Borum, R., \& Wagner, H.R. (2002). Impact of outpatient commitment on victimization of people with severe mental illness. American Journal of Psychiatry, 159, 1403-1411.

Hiday, V.A., Swartz, M.S., Swanson, J., Wagner, H.R. (1997). Patient perceptions of coercion in mental hospital admission. International Journal of Law and Psychiatry, 20, 227-241.

Hiday, VA. (1995). The social context of mental illness and violence. Journal of Health and Social Behavior, $36,122-137$.

Hiday, V.A., Swartz, M.S., Swanson, J.W., Borum, R., \& Wagner, H.R. (1999). Criminal victimization of persons with severe mental illness. Psychiatric Services, 50, 62-68.

Hiday, V.A. (1997). Understanding the connection between mental illness and violence. International Journal of Law and Psychiatry, 20, 399-417. 
Honkonen, T., Henriksson, M., Koivisto, A.M., Stengard, E., \& Salokanas, R.K.R. (2004). Violent victimization in Schizophrenia. Social Psychiatry and Psychiatric Epidemiology, 39, 606-612.

Jones, S.H., Thornicroft, G., Coffey, M., \& Dunn, G. (1995). A brief mental health outcome scalereliability and validity of the Global Assessment of Functioning (GAF). British Journal of Psychiatry, $166,654-659$

Kamal, A. (1995). Variables in expressed emotions associated with relapse. A comparison between depressed and schizophrenic samples in Egyptian Community. Current Psychiatry, 2, 211-215.

Kamel, M., Ghanem, M., Ashour, S., El-Mahalawy, N., \& Al Yahri, A. (1991). Stigma of mental illness. Ain Shams Medical Journal, 12, 477-485.

Kay, S.R., Fiszbein, A., \& Opler, L.A. (1987). The Positive and Negative Syndromes Scales (PANSS) for Schizophrenia. Schizophrenia Bulletin, 13, 261- 276.

Khalil, A.H. (2001). Schizophrenia Across Arab Culture. In An Arab Perspective. Eds, Okasha, A. and Maj, M., World Psychiatric Association. p 65-88,

Klaus, P.A. (2000). Crimes against Persons Age 65 or older, 1992-97 (NCJ176352). Washington, DC: Bureau of Justice Statistics.

Kumpulainen, K. (2008). Psychiatric conditions associated with bullying. International Journal of Adolescent Medicine and Health, 20, 121-132

Lam, J.A. \& Rosenheck, R. (1998). The Effect of Victimization on Clinical Outcomes of Homeless Persons With Serious Mental Illness. Psychiatric Services, 49, 678-683.

Law, M.R., Soumerai, S.B., Ross-Degnan, D., \& Adams, A.S. (2008). A longitudinal study of medication nonadherence and hospitalization risk in schizophrenia. Journal of Clinical Psychiatry, 69, 47-53.

Lehman, A.F. \& Linn, L.S. (1984) Crimes against discharged mental patients in board-and-care homes. American Journal of Psychiatry, 141, 271-274

Lehman AF (1999): Developing an outcomes-oriented approach for the treatment of schizophrenia. Journal of Clinical Psychiatry, 60, 30-35.

Logan, T.K., Walker, R., Cole, J., \& Leukefeld, C. (2002). Victimization and substance abuse among women: contributing factors, interventions, and implications. Review of General Psychology, 6, 325-397.

Marley, J.A., \& Buila, S. (2001). Crimes against people with mental illness: types, perpetrators, and influencing factors. Social Work, 46, 115-124.

Menisini, M., Modena, M., \& Tani, F. (2009). Bullying and victimization in adolescence: concurrent and stable roles and psychological health symptoms. Journal of Genetic Psychology, 170, 115- 133.

Miethe, T.D., \& McDowall, D. (1993). Contextual effects in models of criminal victimization. Social Forces, 71, 741-761.

Okasha, A., Arboleda, F.J., \& Sartorius, N. (2000). Ethics, Culture and Psychiatry: International Perspectives. American Psychiatric Press INC, Washington, London.

Okasha, A. (1999): Mental Health in Middle East: Egyptian PerspectiveClinical Psychology Review, Vol. 19, No. 8, pp. 917-933,

Okasha A. (1988). Okasha's clinical psychiatry. Anglo-Egyptian Bookshop. p. 344.

Okasha, A., El-Akabawi, A., Snyder, K., Wilson, A.K., Youssef, I., el Dawla, A.S. (1994): Expressed emotion, perceived criticism and relapse in depression: a replication in an Egyptian community. American Journal of Psychiatry, 151, 1001-1005.

Okasha, A., Sadek, A., Seif Al Dawla, A., Okasha, T., Sayed, M. \& Youssef, A. (2005). Outcome of Schizophrenia: A Ten-Year Study of a Sample of Egyptian Patients. Egyptian Journal of Psychiatry, 24, 21-32.

Owaida, M., Youssef, I., El Fiky, M., Abu-Ouf, M., Mehasseb, M., \& Medani, A. (1990). Admission outcone of Egyptian schizophrenic patients: A retrospective studies after five and thirty years. Egyptian Journal of Psychiatry, 14, 185-198.

Ragheb, K.., Attia, H., Abdel Wahab, M., El Missiry, A. \& Hussein, R. (2009). Violence agsinst women: Prevalence and Psychological consequences. Egyptian Journal of Psychiatry, 29, 15- 24.

Sampson RJ, Lauristen JL. (1993): Violent victimization and offending : individual, situational, and community-level risk factors. In: Reiss $\mathrm{Aj}$, Roth JA, Miczek KA, eds. Understanding and Preventing Violence: Social Influences. Vol 3. Washington, DC: national and Academy Press, 1-114.

Sartorius N, Gulbinat W. and Harrison G. (1996): Long term follow up of Schizophrenia in 16 Countries: A description of the international study of Schizophrenia conducted by the WHO. Social Psychiatry. Psychiatric Epidemiology, 31, 249- 258.

Shomerus, G., Heider, D., Angermeyer, M.C, Bebbington, P.E., Azorin, J.M., Brugha, T. \& Toumi, M. (2008). Urban Residence, victimhood and the appraisal of personal safety in people with schizophrenia: results from the European Schizophrenia Cohort (Euro SC). Psychological Medicine, 38, 591- 597. 
Silver, E., Arseneault, L., Langley, J., Caspi, A., \& Moffitt TE. (2005). Mental disorder and violent victimization in a total birth cohort. American Journal of Public Health, 95, 2015-2021

Silver, E. (2002). Mental disorder and violent victimization: the mediating role of involvement in conflicted social relationships. Criminology, 40, 191-211.

Teplin, L.A., McClelland, G.M., Abram, K.M, \& Weiner, DA. (2005): Crime Victimization in Adults With Severe Mental Illness. Comparison With the National Crime Victimization Survey. Archives of General Psychiatry, 62, 911-921.

Torrey, E.F. (1999). Medication compliance, letter to the editor. Psychiatric Services, 50, 567.

US Department of Justice (2001). Crime Victimization Survey, 1992-1999, 9th ed. Ann Arbor, Mich, Interuniversity Consortium for Political and Social Research.

Walsh, E., Moran, P., Scott, C., McKenzie, K., Burns, T., Creed, F., Tyrer, P., Murray. RM. \& Fahy T. (2003). Prevalence of violent victimization in severe mental illness. British Journal of Psychiatry, 183:233-8.

Weiden PJ, Kozma C, Grogg A, Locklear J (2004): Partial compliance and risk of rehospitalization among California Medicated patients with schizophrenia. Psychiatr Serv, 55:886-891.

WHO (1999). Report of the Consultation on Child Abuse Prevention, 29-31 March 1999, Geneva, World Health Organization, (document WHO/HSC/PVI/99.1). 